\title{
A randomized comparative study between low-dose magnesium sulphate and standard dose regimen for management of eclampsia
}

\author{
Latika Sahu $^{1 *}$, Shubhra Singh', Anjali Tempe ${ }^{1}$, B. C. Koner ${ }^{2}$ \\ ${ }^{1}$ Department of Obstetrics and Gynecology, Maulana Azad Medical College and associated Lok Nayak Hospital, New \\ Delhi - 110002, India \\ ${ }^{2}$ Department of Biochemistry, Maulana Azad Medical College and associated Lok Nayak Hospital, New Delhi - \\ 110002, India \\ Received: 4 December 2013 \\ Accepted: 15 December 2013 \\ *Correspondence: \\ Dr. Latika Sahu, \\ E-mail: latikasahu@gmail.com \\ (C) 2014 Sahu L et al. This is an open-access article distributed under the terms of the Creative Commons Attribution \\ Non-Commercial License, which permits unrestricted non-commercial use, distribution, and reproduction in any \\ medium, provided the original work is properly cited.
}

\begin{abstract}
Background: Eclampsia is a hypertensive disorder related to pregnancy, in which there is occurrence of one or more generalized convulsions and or coma, in the absence of other neurologic conditions. It is a common obstetric emergency. It contributes significantly to maternal and perinatal morbidity and mortality. Dr. J. A. Pritchard in 1955, introduced magnesium sulphate for control of convulsions in eclampsia and is used worldwide. Considering the low body mass index of Indian women, a low dose magnesium sulphate regime has been introduced by some authors. The Objective was to compare the efficacy of low dose magnesium sulphate regimen with standard Pritchard's regimen for eclampsia.

Methods: A prospective randomized study of fifty eclampsia cases, treated with magnesium sulphate (25 each with low dose regime and Pritchard regime) was carried out from October 2010 to January 2012 at MAMC \& LNH, New Delhi, India. Results were analysed using Statistical Package of Social Sciences (SPSS) software 17.0.

Results: In the present study, convulsions were controlled in $96 \%$ of eclampsia cases with low dose magnesium sulphate regimen. One case i.e. $4 \%$ had single episode of recurrence of convulsion, which was controlled by giving additional drugs and shifted to standard dose regimen. There was no maternal mortality.

Conclusions: The maternal and perinatal morbidity and mortality in the present study were comparable to those of standard Pritchard's regimen. The study did not find a single case of magnesium related toxicity with low dose magnesium sulphate regimen. Low dose magnesium sulphate regimen was found to be safe and effective in eclampsia.
\end{abstract}

Keywords: Eclampsia, Pritchard's regime, Low dose magnesium sulphate

\section{INTRODUCTION}

Eclampsia still remains a common cause of maternal and perinatal morbidity and mortality in underprivileged population. Incidence of eclampsia is one in 2000 deliveries in developed countries and one in 50 to 500 deliveries in developing countries. ${ }^{1}$ In India, the incidence of eclampsia ranges from 6 to 100 per 10,000 live births. ${ }^{2}$ Eclampsia can occur during antepartum
$(35 \%-45 \%)$, intrapartum $(15 \%-20 \%)$, or in postpartum (35\%-45\%) period. ${ }^{3}$ Eclampsia accounts for $12 \%$ of maternal deaths in world and $8 \%$ of maternal deaths in India. ${ }^{4}$ An estimated 50,000 women die each year having had an eclamptic convulsion. ${ }^{5}$

Following publication of collaborative eclampsia trial in 1995 magnesium sulphate must be regarded as the agent of choice as it controls eclamptic convulsions and 
prevents recurrences of convulsions more effectively, reduces maternal \& neonatal morbidity and mortality than diazepam\& phenytoin. ${ }^{6}$ Magnesium has a narrow therapeutic index leading to concerns related to its toxicity. Experience with Pritchard's magnesium sulphate regimen for eclampsia showed multiple toxicity like respiratory, renal and neuromuscular dysfunction and needed dose omission. Adoption of this treatment in primary \& secondary level hospital has been delayed due to fear of toxicity of drug which is linked to high serum magnesium levels and can be life threatening for mother. It may also affect neonatal outcome. Hence studies have been carried out in developing countries to determine the lowest effective dose. ${ }^{7,8}$ Pritchard in 1984 suggested that the dose of magnesium sulphate may be reduced for low BMI women in Asia as administering Pritchard's regimen might prove to be hazardous for them. ${ }^{9}$

Since the introduction of Pritchard's regimen there has been a constant discussion in literature regarding the best therapeutic dose of magnesium sulphate that can keep the patients free from toxicity. Various low dose magnesium sulphate regimens have been described principally because of small size of Indian women \& concern about toxicity in circumstances where facility for measurement of serum level of magnesium is not available. Low dose magnesium sulphate regimen has shown promise in terms of decrease in side effects without a significant decrease in its therapeutic benefits. In India, Pritchard's regimen has been modified in various places and found that low dose regimen was as efficacious as standard dose regimen in convulsion control with less of magnesium toxicity but neither a long term statistical data has been reported nor standardisation of protocol has been framed. ${ }^{1,8,10-13}$

In this study we have used the Pritchard's regimen (intramuscular) as standard dose because it is easier to administer since it is given intramuscularly. Normal serum concentrations of magnesium are 1.5-2.5 meq/L (1.8-3.0 mg/dL). Total magnesium serum concentrations advocated for the treatment of eclamptic convulsions are 3.5-7 mEq/L (4.2-8.4 mg/dL), which can be obtained by administering it intramuscularly, intravenously or a combination of both. ${ }^{14}$ While the IM regimen has the disadvantage of painful injections, it has the advantage of greater convenience and safety. In our setting, pumps for IV infusion are not readily available and, in addition, the nursing staff may be too busy to provide the continuous monitoring required. The IM route, where a dose will only be given once reflexes, respiration and urine output have been checked, is likely to be safer. .

The low dose which we have chosen (Dhaka regimen) for comparison with standard Prichard's regimen because many studies with this regimen showed efficacy similar to Prichard's. This type of study has not been published from north India commonly and had not been used in our institution. So, we have tried to find the efficacy of this low dose regimen which can be tried in our institution \& also can be informed to nearby primary \& secondary health centers to implement this regimen without fear of magnesium toxicity as in standard Pritchard's regimen which can reduce the complications of eclampsia while reaching our tertiary level hospital.

The present study is a prospective randomized control trial with an objective to determine efficacy of low dose magnesium sulphate in convulsion control in cases with eclampsia, to record signs of toxicity of magnesium and serum magnesium levels and comparing with the standard Pritchard's regimen. Both primary and secondary outcome measures were compared with relation to serum magnesium levels also. Most of the prior studies were only observational studies and correlation with serum magnesium levels were not there. Prior studies also did not include all the parameters which we have mentioned in the present study.

\section{METHODS}

This study was carried out in the Department of Obstetrics and Gynecology, Maulana Azad Medical College, and associated Lok Nayak Hospital, New Delhi from September 2010 to January 2012. This is a randomised controlled study involving two groups of patient with eclampsia receiving either low dose (study group) or standard dose (control group) magnesium sulphate regimen.

\section{Method of randomization}

A computer generated table of random numbers is used to assign patients to 1 of 2 treatment groups with a $1: 1$ ratio of control to study subjects. After consenting to participate at the time of enrolment, patients were assigned in numeric order to the corresponding treatment group.

\section{Study design}

Eclampsia was diagnosed if there was history of generalised tonic clonic convulsions with or without elevated blood pressure and proteinuria (by dipstick method) in the absence of any underlying seizure disorders after 20 weeks of gestational age. All cases of antepartum, intrapartum and postpartum eclampsia, presenting in obstetric emergency, labour rooms and/or wards who gave informed consent to participate in the study were included in the study. Eclampsia patients who had renal failure, severe pulmonary edema with respiratory failure, having received magnesium sulphate and/or other anticonvulsant before coming to our hospital, cerebrovascular accident and Disseminated Intravascular Coagulation (DIC) were excluded from the present study.

The primary outcome measures for this study were-To determine efficacy of low dose magnesium sulphate in the management of eclampsia. To determine recurrent convulsion rate and magnesium toxicity in eclampsia 
patients receiving low dose and standard dose magnesium sulphate group, to compare serum magnesium levels of patients in low dose and standard dose group at $0 \mathrm{~min}$, at 5 mins, 4 hours after loading dose and before last dose of magnesium sulphate administration and if any time toxicity occurs.

The secondary outcome measures for this study were-To study maternal and perinatal outcomes in low dose and standard dose magnesium sulphate group. Maternal outcome include- complications, and mode of delivery. Perinatal outcomes include - APGAR score at 0, 1, 5 minutes of birth, complications-asphyxia, RDS.

After exclusion 50 patient with eclampsia were included in the study, after randomization 25 patients were given low dose regimen and 25 patients were given standard dose regimen. Low dose regimen protocol includes loading dose-4gms of magnesium sulphate (20\% solution) given intravenously slowly (15 mins) and $3 \mathrm{gms}$ of magnesium sulphate $(50 \%$ solution $)$ given intramuscularly in each buttock. Subsequently magnesium sulphate maintenance dose of $2.5 \mathrm{gm}(50 \%$ solution) given every 4 hourly intramuscularly in alternate buttock. Standard dose regimen (Pritchard's) protocol include $4 \mathrm{gms}$ of magnesium sulphate (20\% solution) given intravenously slowly (15 mins) and $5 \mathrm{gms}$ of magnesium sulphate $(50 \%$ solution $)$ given intramuscularly in each buttock. Subsequently magnesium sulphate maintenance dose of $5 \mathrm{gm}(50 \%$ solution) given every 4 hourly intramuscularly in alternate buttock.

In both groups maintenance dose was given until $24 \mathrm{hrs}$ after last convulsion or delivery whichever was later. In both the groups if convulsions occurred within four hours after the loading dose then it was said to be recurrence of convulsions and additional dose of $2 \mathrm{gm}$ i.v. slowly magnesium sulphate was given and previous dose schedule were continued. In low dose group if convulsions were not controlled after repeating two successive doses of $2 \mathrm{gm}$ magnesium sulphate then cases were shifted to standard dose regimen and were labelled as failure of low dose regimen. In standard dose group same regimen was followed for recurrence of convulsion and if convulsion was not controlled with two successive dose of $2 \mathrm{gm}$ i.v. magnesium sulphate other anticonvulsant (diazepam/ phenytoin) were added and CT/MRI brain was performed to rule out seizure disorder.

Cases were monitored just before each maintenance dose for evidence of magnesium toxicity by observing deep tendon reflexes (DTR)/knee jerk reflexes, urinary output and respiratory rate. By patient's condition other clinical parameters were checked and guidelines for management of eclampsia were followed. Maintenance doses were deferred if DTR absent, or urine output $<100 \mathrm{ml}$ in $4 \mathrm{hrs}$ or respiratory rate $<16 / \mathrm{min}$.
In all cases detailed history regarding high Blood pressure (BP) recordings and medications taken, headache, blurring of vision, epigastric pain, number of convulsions, history of preeclampsia/eclampsia in previous and present pregnancy were noted. General physical examination included assessing patient's Glasgow coma score (GCS), vital signs, blood pressure recording, pallor, edema, cyanosis and systemic examination included respiratory, cardiovascular and neurological examination. Obstetrical, pelvic examination and bishop scoring was done. Laboratory investigations done were blood group and $\mathrm{Rh}$ type, hemogram, platelet count, liver function tests, kidney function tests, serum electrolytes, coagulation profile and fundus examination and urine examination for protein.

After stabilization of the patient, Induction/augmentation of labor was done in all cases of antepartum and intrapartum eclampsia. If diastolic BP was higher than $120 \mathrm{mmHg}$ intravenous Labetalol was used. Severe hypertension was treated with oral Labetalol. Cesarean section was performed for obstetrical indications. All patients were weighed on $4^{\text {th }}$ postpartum day .Birth weight of the baby, APGAR score at 0, 1, 5 min and neonatal outcome were recorded.

Blood samples were collected for measurement of serum magnesium levels at $0 \mathrm{hr}, 5 \mathrm{mins}$ after the loading dose, 4 hrs (just before the first maintenance dose), just before last dose. Additional sample were taken if symptoms of magnesium toxicity appear / recurrent convulsion occur.

Serum magnesium levels were estimated by dye binding assay using Randox commercial kit adopted to beckman coolter synchron $\mathrm{C}_{\mathrm{x}} 5$ random access clinical chemistry analyser. Magnesium ion reacted with xylidyl blue in an alkaline medium to form a water soluble purple red chelate, the colour intensity of which was proportional to the concentration of magnesium in the sample. Interference of calcium was excluded from the reaction by complexing with E.G.T.A. Clinical findings of the patients were correlated with serum magnesium levels.

\section{Statistics}

The chi square/fisher's exact test was used to determine the statistical significance for the categorical variables where as unpaired t test / Mann Whitney test was used for continuous variables. A $P$ value $\leq 0.05$ was taken as a level of statistical significance. Data were analysed using SPSS PC version 17.0 (statistical software).

\section{Ethics}

This study had the approval of Hospital Research Ethics Committee and written informed consent was obtained from every patient's relative. 


\section{RESULTS}

There were total 73 eclampsia cases admitted to the hospital during the study period and after exclusion only fifty cases met the inclusion criteria and were randomised into two groups ( 25 in each group) to receive either low dose or standard dose magnesium sulphate regimen.

Table 1 shows the patient characteristics of both the groups. There were no patients of intrapartum eclampsia. The age distribution, type of eclampsia, antenatal booking and gravid status, period of gestation, BMI, was similar in both the groups. Majority of booked patients were of postpartum eclampsia. There were no patients of BMI > 25 in both groups.

The GC score at presentation, systolic and diastolic BP, number of convulsions, antepartum eclampsia patients in labour at the time of admission, presence of pedal edema, development of papilledema, proteinuria and cesarean section rate was similar in both groups. There was no maternal mortality observed in either of the group. The hematological and liver \& biochemical parameters were comparable in both the groups. Table 1 also depicts mean number of magnesium sulphate doses and total cumulative dose of magnesium sulphate received by patients in both groups.

Table 1: Patient characteristics and study parameter in both the groups ${ }^{*}$.

\begin{tabular}{|c|c|c|c|}
\hline & $\begin{array}{l}\text { Low dose group } \\
(\mathbf{n}=\mathbf{2 5})\end{array}$ & $\begin{array}{l}\text { Standard dose group } \\
(\mathbf{n}=\mathbf{2 5})\end{array}$ & P value \\
\hline Age in years & $23.64 \pm 3.23$ & $22.6 \pm 2.46$ & 0.57 \\
\hline Antepartum eclampsia & $20(80 \%)$ & $20(80 \%)$ & \multirow[b]{2}{*}{1} \\
\hline Postpartum eclampsia & $5(20 \%)$ & $5(20 \%)$ & \\
\hline Gravida status - Primigravida & $20(80 \%)$ & $19(76 \%)$ & 0.705 \\
\hline Antenatal booking - Booked & $2(8 \%)$ & $4(16 \%)$ & 0.384 \\
\hline Period of gestation & $34 \pm 3.85$ weeks & $34 \pm 3.18$ weeks & 0.357 \\
\hline $\operatorname{BMI}\left(\mathrm{Kg} / \mathrm{m}^{2}\right)$ & $20.75 \pm 1.33$ & $20.64 \pm 1.24$ & 0.764 \\
\hline Glasgow coma score & $12.08 \pm 2.48$ & $12.12 \pm 2.24$ & 0.93 \\
\hline Pedal edema present & $21(84 \%)$ & $22(88 \%)$ & 0.68 \\
\hline Systolic BP (in mmHg) & $159.6 \pm 17.2$ & $164 \pm 14.14$ & 0.32 \\
\hline Diastolic $\mathrm{BP}$ (in $\mathrm{mmHg}$ ) & $104.8 \pm 9.48$ & $103.4 \pm 9.26$ & 0.29 \\
\hline Nubmer of convulsions & $6.08 \pm 2.61$ & $6.4 \pm 2.66$ & 0.67 \\
\hline In labour at the time of presentation & $12(60 \%)$ & $14(70 \%)$ & 0.651 \\
\hline Fundus examination- Papilledema & $1(4 \%)$ & $2(8 \%)$ & 0.552 \\
\hline Distribution of proteinuria - Nil & $5(20 \%)$ & $5(20 \%)$ & \multirow{6}{*}{0.337} \\
\hline Trace & $3(12 \%)$ & $3(12 \%)$ & \\
\hline $1+$ & $2(8 \%)$ & $8(32 \%)$ & \\
\hline $2+$ & $9(36 \%)$ & $6(24 \%)$ & \\
\hline $3+$ & $5(20 \%)$ & $3(12 \%)$ & \\
\hline $4+$ & $1(4 \%)$ & $0(0 \%)$ & \\
\hline Mode of delivery- vaginal & $21(84 \%)$ & $20(80 \%)$ & 0.99 \\
\hline \multicolumn{4}{|l|}{ Magnesium sulphate } \\
\hline Mean number of doses given & $9.6 \pm 1.97$ & $9.04 \pm 1.69$ & 0.29 \\
\hline Mean Total cumulative dose (gms) & $31.5 \pm 4.94(25-40)$ & $54.2 \pm 8.47(39-64)$ & 0.001 \\
\hline (Range of total magnesium given) & & $95 \%$ C.I. $18.75-26.64$ & \\
\hline
\end{tabular}

*Values are expressed as mean \pm SD or frequency (\%) / number (percent)

Treatment complication in women receiving magnesium sulphate for eclampsia was depicted in Table 2. Patients who developed pulmonary edema, aspiration pneumonitis were managed medically in ICU. No patient had renal failure, intracranial hemorrhage, cortical blindness, paralysis or postpartum hemorrhage in either of the groups. Prevalence of loss of DTR was significantly higher in standard dose group as compared to low dose group. In low dose group the mean time after loading dose at which DTR were lost was 9 hours and the mean serum magnesium levels at that time was $4.05 \mathrm{mg} / \mathrm{dl}$. In standard dose group the mean time after loading dose at which DTR were lost was 9.3 hours and the mean serum magnesium levels at that time was $4.7 \mathrm{mg} / \mathrm{dl}$.

In low dose group 12 hours after loading dose 1 (4\%) patient developed oliguria and the mean serum magnesium levels at that time was $5.0 \mathrm{mg} / \mathrm{dl}$. In standard dose group $5(20 \%)$ patients developed oliguria. The mean time after loading dose at which oliguria developed 
was 8 hours and the mean serum magnesium levels at that time were $5.1 \mathrm{mg} / \mathrm{dl}$. Twenty $(80 \%)$ patients in low dose group and $15(60 \%)$ patients in standard dose group had received complete dose of magnesium sulphate. There was one $(4 \%)$ convulsion recurrence in low dose group which occurred 3 hours after the loading dose. Serum magnesium level at that time was $4.9 \mathrm{mg} / \mathrm{dl}$.

Table 2: Treatment complication in women receiving magnesium sulphate for eclampsia**.

\begin{tabular}{|llll|}
\hline $\begin{array}{l}\text { Variable } \\
\text { group }\end{array}$ & $\begin{array}{l}\text { Low dose } \\
\text { group } \\
(\mathbf{n = 2 5})\end{array}$ & $\begin{array}{l}\text { Standard } \\
\text { dose group } \\
(\mathbf{n}=\mathbf{2 5})\end{array}$ & P value \\
\hline $\begin{array}{l}\text { Loss of knee } \\
\text { jerk reflex }\end{array}$ & $4(16 \%)$ & $11(44 \%)$ & 0.031 \\
\hline Oliguria & $1(4 \%)$ & $5(20 \%)$ & 0.082 \\
\hline $\begin{array}{l}\text { Seizure } \\
\text { recurrence }\end{array}$ & $1(4 \%)$ & 0 & 1.000 \\
\hline $\begin{array}{l}\text { Pulmonary } \\
\text { edema }\end{array}$ & $2(8 \%)$ & $3(12 \%)$ & 0.63 \\
\hline $\begin{array}{l}\text { Aspiration } \\
\text { pneumonitis }\end{array}$ & $1(4 \%)$ & $0(0 \%)$ & 0.32 \\
\hline Number of deferred doses & & \\
\hline 1 & 3 & 6 & 0.12 \\
\hline 2 & 2 & 1 & \\
\hline 3 & 20 & 15 & \\
\hline $\begin{array}{l}\text { No doses } \\
\text { deferred }\end{array}$ & 20 & & \\
\hline
\end{tabular}

${ }^{* *}$ Values are given as number (percent) unless otherwise indicated.
Table 3 depicts maternal serum magnesium levels. There was a similar statistically significant rise in magnesium levels obtained after administration of loading dose in both groups. A statistically significant higher level of serum magnesium was seen at 5 mins, 4 hours after loading dose and before last dose of magnesium sulphate administration in standard dose group as compared to low dose group. The range of serum magnesium levels was 2.3 to $6.2 \mathrm{mg} / \mathrm{dl}$ (mean $4.04 \mathrm{mg} / \mathrm{dl}$ ) in standard dose group and 1.9 to $5.3 \mathrm{mg} / \mathrm{dl}$ (mean $3.63 \mathrm{mg} / \mathrm{dl}$ ) in low dose.

Figure 1 shows line diagrams to compare the mean serum magnesium levels of patients in low dose and standard dose group at $0 \mathrm{~min}$, at $5 \mathrm{mins}, 4$ hours after loading dose and before last dose of magnesium sulphate administration.

Table 4 depicts perinatal outcome. Birth weight, still birth rate, babies requiring NICU (Neonatal Intensive Care Unit) care, neonatal death rate, respiratory distress and APGAR score were comparable in both the groups. The cause of neonatal death was sepsis and birth asphyxia. Hypotonia was not observed in new born in any of the group.

Table 3: Maternal serum magnesium level in women treated with magnesium sulphate for eclampsia ${ }^{* * *}$.

\begin{tabular}{|ll|lllll|}
\hline & $\begin{array}{l}\text { Low dose } \\
\text { group }(\mathbf{n = 2 5})\end{array}$ & $\begin{array}{l}\text { Standard dose } \\
\text { group }(\mathbf{n = 2 5})\end{array}$ & $\begin{array}{l}\text { Difference } \\
\text { of means }\end{array}$ & $\begin{array}{l}\text { 95\% C.I. } \\
\text { upper }\end{array}$ & $\begin{array}{l}\text { 95\% C.I. } \\
\text { lower }\end{array}$ & P value \\
\hline $0 \mathrm{hr}$ & $2.19 \pm 0.46$ & $2.07 \pm 0.41$ & 0.11 & 0.12 & 0.36 & 0.339 \\
\hline $5 \mathrm{~min}$ & $4.20 \pm 0.39$ & $5.15 \pm 0.49$ & 0.94 & 1.19 & 0.68 & 0.000 \\
\hline $4 \mathrm{hr}$ & $4.42 \pm 0.36$ & $4.80 \pm 0.47$ & 0.38 & 0.62 & 0.14 & 0.002 \\
\hline $\begin{array}{l}\text { Just before } \\
\text { last dose }\end{array}$ & $3.64 \pm 0.55$ & $4.17 \pm 0.63$ & 0.53 & 0.87 & 0.19 & 0.003 \\
\hline
\end{tabular}

${ }^{* * * *}$ Values are given in milligram per deciliter of serum and expressed as mean \pm SD unless otherwise indicated

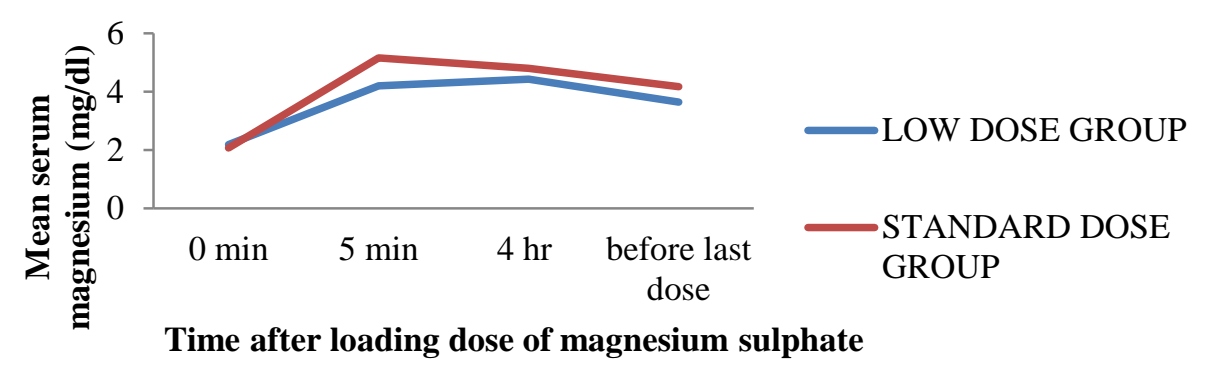

Figure 1: Comparison of mean serum magnesium in low and standard dose group. 
Table 4: Perinatal outcome following maternal treatment with magnesium sulphate for eclampsia ${ }^{* * * *}$.

\begin{tabular}{|c|c|c|c|}
\hline & $\begin{array}{l}\text { Low dose } \\
\text { group }(n=25)\end{array}$ & $\begin{array}{l}\text { Standard } \\
\text { dose group } \\
(n=25)\end{array}$ & $\begin{array}{l}P \\
\text { value }\end{array}$ \\
\hline \multicolumn{4}{|c|}{ Birth weight (gm) } \\
\hline$<1500$ & $2(8 \%)$ & $6(24 \%)$ & 0.40 \\
\hline $1500-2500$ & $15(60 \%)$ & $11(44 \%)$ & \\
\hline$>2500$ & $8(32 \%)$ & $8(32 \%)$ & \\
\hline Mean \pm SD & $2050.6 \pm 697.7$ & $2187.7 \pm 423.7$ & \\
\hline Still birth & 6 & 7 & 0.74 \\
\hline $\begin{array}{l}\text { NICU care } \\
\text { requirement }\end{array}$ & 5 & 7 & 0.58 \\
\hline $\begin{array}{l}\text { Respiratory } \\
\text { distress }\end{array}$ & 19 & 15 & 0.50 \\
\hline $\begin{array}{l}\text { APGAR } \\
(0 \mathrm{~min}) \leq 7\end{array}$ & $6(31.6 \%)$ & $8(68.4 \%)$ & 0.50 \\
\hline Mean \pm SD & $8.21 \pm 1.03$ & $7.95 \pm 1.17$ & \\
\hline $\begin{array}{l}\text { APGAR } \\
(1 \mathrm{~min}) \leq 7\end{array}$ & $5(26.3 \%)$ & $7(38.9 \%)$ & 0.48 \\
\hline Mean \pm SD & $8.32 \pm 1.15$ & $8.05 \pm 1.02$ & \\
\hline $\begin{array}{l}\text { APGAR } \\
(5 \mathrm{~min}) \leq 7\end{array}$ & $3(15.8 \%)$ & $6(33.3 \%)$ & 0.25 \\
\hline Mean \pm SD & $8.63 \pm 0.76$ & $8.32 \pm 1.05$ & \\
\hline
\end{tabular}

${ }^{* * * *}$ NICU - Neonatal intensive care unit, values are given as number (percent) unless otherwise specified

\section{DISCUSSION}

Maternal age of less than 20 years is the strongest risk factor for eclampsia. In the present study, one case in low dose group and 3 cases in standard dose group were less than 20 years of age but 21 patients in low dose group and 19 patients in standard dose group were between 20 25 years of age. Bangal et al. Sardesai et al. reported that $44 \%, 46 \%$ of cases respectively below 20 years of age. ${ }^{2,10}$ Eclampsia is a disease of primigravida. In this study, $80 \%$ and $76 \%$ of eclampsia patient in low dose and standard dose group respectively were primigravida. In the study by Bangal et al. Pritchard et al. and Sardesai et al. in their studies observed $80 \%, 75 \%$, and $79 \%$ of eclampsia cases in primigravidas respectively. ${ }^{2,9,10}$ In this study $80 \%$ were antepartum and $20 \%$ were postpartum eclampsia in both the group. In the study by Bangal et al. $60 \%$ of cases had antepartum, $28 \%$ cases had intrapartum and $12 \%$ cases had postpartum eclampsia. ${ }^{2}$ In this study $92 \%$ of low dose and $84 \%$ of standard dose group were unbooked cases. In the study by Bangal et al. Sardesai et al. 92\%, 76.6\% of cases were unbooked respectively. ${ }^{2,10}$

In this study there was one convulsion recurrence in low dose group at serum magnesium level of $4.9 \mathrm{mg} / \mathrm{dl}$ which lies within therapeutic range similar to other studies. ${ }^{15}$ Pritchard and Sibai have reported recurrence rates of 12 $\%$ and $14 \%$ respectively. ${ }^{9,16}$ The recurrence rate reported in collaborative eclampsia trial using Pritchard's regimen ranged between 5.7 and $13.2 \%$. $^{3}$ Begum and colleagues using low dose regimen reported only one out of 65 cases had recurrent convulsion. ${ }^{8}$ Recurrence convulsion rate in various Indian studies using low dose regimen is reported in the range of 5 to $10 \% .^{2,10-12}$ Studies using single loading dose of magnesium sulphate also observed recurrence convulsion rate ranging $7.4 \%$ to $15 \%$, which is higher than low dose or standard dose group, thus supporting the requirement of maintenance dose of magnesium sulphate in eclampsia. ${ }^{17}$

There was no maternal mortality observed in this study in either group which was similar in other Indian studies. ${ }^{11,12}$ Pritchard, Seth et al and collaborative eclampsia trial reported maternal mortality in eclampsia to be $0.4 \%, 7.6 \%$ and $2.6-3.8 \%$ respectively. ${ }^{9,1,7}$ Maternal mortality in study by Sardesai and colleagues, Begum et al. using low dose magnesium sulphate regimen was $2.63 \%$ and nil respectively. ${ }^{8,10}$

In the Pritchard's study 4 patients (1.6\%) had serious respiratory depression. ${ }^{9}$ Magnesium toxicity profile correlates with its serum levels and an early sign of its toxicity is loss of DTR, which is followed by respiratory failure and cardiac arrhythmias at higher levels. ${ }^{9}$ Dose omissions at loss of DTR is necessary to prevent subsequent respiratory arrest. In this study no patient in either group had developed respiratory depression, however loss of DTR was observed in $16 \%$ in low dose and $44 \%$ in standard dose group and further doses were omitted. Thus, evidence consistent with magnesium toxicity was observed even with the low dose magnesium sulphate regimen and definitely with standard dose regimen, the results suggesting a need to lower the dose of magnesium sulphate. In the low dose magnesium sulphate regimen by Begum and colleagues, Mahajan and colleague, maintenance dose was omitted in $9 \%$ and 41 $\%$ respectively due to loss of DTR. ${ }^{8,13}$ Study by Shilva and colleagues showed loss of DTR was $8 \%$ and $32 \%$ in low dose and standard dose group respectively $(\mathrm{p}=0.03){ }^{11}$

In this study in 5 patients of low dose and 10 patients in standard dose group maintenance dose of magnesium sulphate was omitted due to clinically apparent loss of DTR or oliguria. In Mahajan and colleagues using low dose magnesium sulphate regimen, $41 \%$ cases maintenance dose of magnesium sulphate was omitted due to loss of DTR and oliguria. ${ }^{13}$ In study by Shilva and colleagues $12 \%$ patient in low dose group and $52 \%$ patients in standard dose group, maintenance dose of magnesium sulphate was deferred. ${ }^{11}$ The findings of our study is consistent with other studies.

In literature there are very few studies which measured serum magnesium levels in eclampsia. In present study serum magnesium levels were significantly higher in standard dose group. Therapeutic ranges of serum magnesium by some authors recommend 4.8 to $8.4 \mathrm{mg} / \mathrm{dl}$ while Pritchard's described as being 2 to $3.5 \mathrm{mmol} / \mathrm{L} .{ }^{18,19}$ 
The serum magnesium levels in present study in both the groups were within the therapeutic range described by Pritchard. Magnesium levels obtained in low dose regimen used by Begum and colleagues, Bangal and colleagues was 2.1 to $6 \mathrm{mg} / \mathrm{dl}$ and $4.16-4.38 \mathrm{meq} / \mathrm{l}$ respectively using low dose regimen. ${ }^{8,12}$ In study by Shilva and colleagues range of magnesium was 2.08 to $3.69 \mathrm{mg} / \mathrm{dl}$ in low dose group and 2.0 to $4.3 \mathrm{mg} / \mathrm{dl}$ in standard dose group. ${ }^{11}$

In low dose group 12 hours after loading dose oliguria developed at mean serum magnesium levels of $5.0 \mathrm{mg} / \mathrm{dl}$. In standard dose group 8 hours (mean) after loading dose oliguria developed at mean serum magnesium levels of $5.1 \mathrm{mg} / \mathrm{dl}$. Serum magnesium levels were within therapeutic levels at the time of oliguria. In Mahajan and colleagues study using low dose magnesium sulphate regimen, 3 patients developed oliguria.

In low dose group 9 hours (mean) after loading dose DTR were lost at the mean serum magnesium levels of 4.05 $\mathrm{mg} / \mathrm{dl}$. In standard dose group 9.3 hours (mean) after loading dose DTRs were lost at the mean serum magnesium levels of $4.7 \mathrm{mg} / \mathrm{dl}$. The earliest sign of toxicity loss of DTR, generally occur when serum levels $>8 \mathrm{mg} / \mathrm{dl} .{ }^{19}$ In present study mean serum magnesium levels at loss of DTR was below levels that would produce toxicity and this could be explained by higher sensitivity of low BMI women to magnesium toxicity. A study from Thailand suggested that, clinical assessment of DTR, respirations and urine output is adequate to monitor maternal magnesium toxicity without the need to determine actual maternal serum levels. ${ }^{20}$ In study by Begum and colleagues mean time after loading dose at which DTR was lost was 11 hour at mean serum magnesium levels of $3.42 \mathrm{mg} / \mathrm{dl}$. $^{8}$

Definitive treatment of eclampsia is termination of pregnancy. Cesarean section rate in low dose and standard dose group was observed to be $16 \%$ and $20 \%$ respectively in the present study. Cesarean section rate in collaborative eclampsia trial was 66 to $72 \%$ using standard Pritchard's regimen. ${ }^{7}$ Cesarean section rate reported by Begum and colleagues, Mahajan et al, and Sardesai et al using low dose study was $84 \%, 66 \%, 13 \%$ respectively. ${ }^{8-10}$

Neonatal outcome depends on severity of associated intrauterine growth retardation (IUGR), gestational age, birth weight and the level of facilities in NICU. The perinatal mortality rate in low dose and standard dose group was $28 \%$ and $36 \%$ respectively in the present study. Birth asphyxia was observed in $15.3 \%$ in low dose and $33.3 \%$ in standard dose group. Similar results have been shown by other Indian studies comparing the two regimens. ${ }^{1,2,5,8,10-13}$ Collaborative eclampsia trial using standard dose regimen found perinatal mortality rate of $24-26 \%$ and birth asphyxia of $44-48 \%$ in eclampsia. ${ }^{7}$ Thus low dose magnesium sulphate is no inferior to standard dose regimen in preventing adverse perinatal outcome. Low dose magnesium sulphate has comparable efficacy as standard dose in convulsion control and preventing adverse maternal and perinatal events, with less magnesium toxicity and achieved serum magnesium levels within therapeutic range for convulsion control in eclampsia. Serum magnesium levels lies within therapeutic levels at clinical signs of magnesium toxicity, showing higher sensitivity of low BMI women to magnesium toxicity. We recommend the routine use of low dose magnesium sulphate regimen in low BMI Indian population for convulsion control in eclampsia. However larger multicenter trials are required to prove the efficacy of low dose magnesium sulphate regimen.

\section{Limitations of this study}

The numbers of cases were less for the study as we had to exclude those cases who had already received magnesium sulphate before reaching this tertiary Institution. However this study can add to the literature regarding the efficacy of low dose magnesium sulphate in Indian population.

\section{Future research directions}

Further studies are needed to identify the therapeutic range of serum magnesium and levels at which toxicities occurs. Larger trials with multiple institutional trials can be undertaken to find the lowest effective dose of magnesium sulphate for convulsion control.

\section{Funding: Maulana Azad Medical College Research fund Conflict of interest: None declared}

Ethical approval: The study was approved by the Hospital Research Ethics Committee

\section{REFERENCES}

1. Seth S, Nagrath A, Singh DK. Comparison of low dose, single loading dose and standard Pritchard regimen of magnesium sulphate in ante-partum eclampsia. Anatol J Obstet Gynecol. 2010;1(1):1-4.

2. Bangal V B, Purushottam A. Giri, Satyajit P. Gavhane. A study to compare the efficacy of low dose magnesium sulphate regime with Pritchard regime in eclampsia. IJBAR. 2012;3(1):53-7.

3. Fernando Arias. Hypertensive disorder in pregnancy; Practical Guide to High Risk pregnancy and delivery. 3rd ed. New Delhi: Elsevier publishers;2008:397437.

4. Ministry of Health and Family Welfare, India. Annual Report. New Delhi: 2005: 105-111. Available at: http://mohfw.nic.in/WriteReadData/1892s/69601445 09Annual\%20Report\%20to\%20the\%20People\%20o n\%20Health.pdf. Accessed December 2011.

5. Bhargava A, Pant R, Chutani I, Singh S R. In search for accelerated recovery from eclampsia. J Obstet and Gynecol India. 2006;56:402-5.

6. Montan S. Medical prevention of pre-eclampsia. Acta Obstet Gynaecol Scand Suppl. 1997;76(164):111-5. 
7. Duley L. The Eclampsia Trial collaborative Group. Which Anticonvulsant for women with Eclampsia? Evidence from the Collaborative Eclampsia trial Lancet. 1995;345:1455-63.

8. Begum R, Begum A, Johanson R, Ali MN, Akhtar S. A low dose ("Dhaka") Magnesium Sulphate regimen for Eclampsia. Acta Obstet Gynecol Scand. 2001;80(11):998-1002.

9. Pritchard JA, Cunningham, FG Pritchard SA. The Parkland Memorial Hospital protocol for treatment of eclampsia evaluation of 245 cases. Am J Obstet Gynecol. 1984:148(7);951-63.

10. Sardesai S, Maira S, Patil A. Low dose Magnesium Sulphate therapy for Eclampsia and imminent Eclampsia - regimen tailored for Indian women. J Obstet and Gynecol India. 2003;53(6):546-50.

11. Shilva, Saha SC, Kalra J , Prasad R. Safety and efficacy of low dose magnesium sulphate in the treatment of Eclampsia. Int $\mathbf{J}$ Gynecol Obstet. 2007;97(2):150-1.

12. Bangal V, Kwatra A, Raghav S and Jadhav S. Low dose magnesium sulphate regime for Eclampsia. Pravara Med Rev. 2009;4(3):13-5

13. Mahajan NN, Thomas A, Soni RN, Gaikwad NL and Jain S M. 'Padhar Regime' - a low dose magnesium sulphate treatment for eclampsia. Gynaecol Obstet Invest. 2009;67(1):20-4.

14. Sibai BM, Graham JM, McCubbin JH. A comparison of intravenous and intramuscular magnesium sulfate regimens in preeclampsia. Am J Obstet Gynecol 1984;150:728-33.
15. Duley LW, Crowther CA, Middleton P, Marret S, Rouse D. Magnesium sulphate for women at risk of preterm birth for neuroprotection of the fetus. Cochrane Database Syst Rev. 2009 Jan;21(1):CD004661.

16. Sibai BM. Magnesium sulfate is the ideal anticonvulsant in preeclampsia - eclampsia. Am J Obstet Gynecol. 1990;162(5):1141-5.

17. Ekele BA, Muhammed D, Bello L N, Namadina IM. Magnesium sulfate therapy in Eclampsia : the Sokoto (ultra short) regimen. BMC Res Notes. 2009;2:165.

18. Shokry M, Elsedfy GO, Bassiouny MM, Anmin M, Abozid H. Effects of antenatal magnesium sulphate therapy on cerebral and systemic hemodynamics in preterm newborns. Acta Obstetrica et Gynaecologica. 2010;8(6)9:801-6.

19. Duley L. Magpie Trial Follow up Collaborative group. The Magpie Trial: A randomized trial comparing magnesium sulphate with placebo for preeclampsia: Outcome for children at 18 months. $\mathrm{Br}$ J Obstet Gynaecol. 2007;114(3):289-99.

20. Chinayon P. Clinical management and outcome of eclampsia at Rajavithi Hospital. J Med Assoc Thai. 1998;81(8):579-85.

DOI: $10.5455 / 2320-1770 . i j r \operatorname{cog} 20140316$

Cite this article as: Sahu L, Singh S, Tempe A,

Koner BC. A randomized comparative study between low-dose magnesium sulphate and standard dose regimen for management of eclampsia. Int J Reprod Contracept Obstet Gynecol 2014;3:79-86. 